\title{
Isomorphic pressures of Cluster Institutions on ERP adoption: A study in SME cluster of Indian knitwear industry
}

\author{
Elangovan $\mathbf{N}$ \\ Christ University, Bengaluru, India \\ Correspondence should be addressed to: Elangovan N; elangovan.n@christuniversity.in \\ Received date: 16 January 2015; Accepted date: 14 May 2015; Published date: 27 November 2015 \\ Academic Editor: Sandro Geric \\ Copyright (C 2015. Elangovan N. Distributed under Creative Commons CC-BY 4.0

\begin{abstract}
The demand for more productivity, cost efficiency and the competition has forced the knitwear garments cluster to adopt technologies such as ERP. The knitwear garment industry acts as a cluster and possesses unique characteristics. The industrial clusters experience an institutional isomorphic pressure that forces them to be homogeneous and adopt similar technologies. The study is proposed to answer the question that with the external pressure on them, how absorptive capacity does play a role in ERP adoption. A conceptual model was developed for the study and a survey was conducted among the knitwear garment firms. The data was analysed using structural equation modelling technique. To test the mediation effect, direct, indirect and total effects of the variables were calculated using the AMOS software. The results show that there is a direct influence of isomorphic pressure on ERP adoption and the absorptive capacity mediates in such a way that it complements the institutional forces in ERP adoption. The implication of the study is discussed and finally the paper concludes with the limitations of the study and the future direction for further research.
\end{abstract}

Keywords: Knitwear Garments Cluster, ERP adoption, Institutional isomorphic pressures, Absorptive capacity, Mediation effect.

\section{Introduction}

Industrial clusters are geographic concentration of interconnected companies and institutions in a particular field. Clusters by their collective strength provide competitiveness within the countries as well as across the national borders (Porter, 1998). However, there is competition and cooperation within the units of the cluster. Porter identifies that there is a sheer pressure in the form of competitive pressure and peer pressure. Competitive pressure is the rivalry to win and retain customers. Peer pressure arises when companies need to have similar characteristics to be part of the cluster. This peer pressure can be identified as the institutional isomorphic pressure described by DiMaggio and Powell (1983). Isomorphism is the state of being identical or similar form, shape or structure. Each 
organisation, thriving to match one another provides a collective rationality among them. Organizations conform to the rules and belief systems prevailing in the environment in order to survive and this turns into pressure.

Enterprise Resource Planning (ERP) system is an innovative strategic information system that is essentially a packaged software application that replaces a firm's disparate transaction processing systems with a single, integrated system, embodying the newly understood tight interdependencies among a firm's functional units (Ross and Vitale, 2000). The factors in the adoption of innovative strategic information system like ERP are studied under various perspectives (Poba-Nzaou et al., 2008). The diffusion agents acting from the external to the organization that are part of the institution, combine together to generate a strong isomorphic pressure that forces organizations to adopt ERP and thus comply with the institutionalized management practices (Wood, and Caldas, 2001).

Tirupur is the Knitwear garments cluster of India. The interesting fact about Tirupur cluster is that it is organized in a web of small work places through which the entire town works like a living industrial organization (Chari, 2000). Firms in this cluster include small, medium and largesized garment making and subcontracting units. The unique characteristic of the cluster is that it is a naturally formed cluster because of the availability of good quality cotton in the region. The entrepreneurial spirit encouraged the agrarian community to vertically move up the value chain and establish the knitwear industry. The cluster has vertically integrated to produce high quality fashion knitwear garments.

PricewaterhouseCoopers made a diagnostic study of Information and communication technology (ICT) in Textiles Clusters for the National Manufacturing Competitiveness Council under Project Vikas in 2007-08. The study revealed that the Tirupur knitwear garments cluster is a somewhat matured cluster and many firms have adopted Information Technology (IT) to a great or small extent. Small firms have basic finance and accounting solutions; slightly larger firms use some order tracking systems. Firms that operate on a bigger scale have custom-built or in-house solutions that are developed in conjunction with a third party. Only a few of the large export units, with a turnover of INR 100 crore or more, are mature enough to use full-featured ERP software ("Tirupur Knitwear Cluster", n.d.).

Pouder and St. John (1996) are of the view that geographical clusters will have different rate of adoption of innovation compared to the larger industrial population. In addition, the uniqueness of the knitwear garment cluster makes it necessary to understand the factors in ERP adoption. The high entrepreneurial spirit of the cluster has produced a high disintegration at various stages of garment production. This has not only created a need for ERP for better coordination between internal and external processes but also pose a challenge for ERP adoption. Having transformed from the agricultural background, their absorptive capacity and attitude towards technology adoption need to be studied. The vertical structure and high business growth of the cluster has attracted many players to operate in the cluster. These players have institutionalised to exert a pressure on the firms of the cluster. The cluster mainly operates on the made-to-order (MTO) production system and depends on the international buyers even from the stage of designing. The cluster does not have an international brand or fashion designing facility. Heavy dependence of the firms on the buyers makes them weak not only in price negotiations but also on many decisions.

All these characteristics lead to an interesting question whether the Institutional isomorphic pressures in SME garments cluster promote ERP adoption. We try to address this question in this study and try to test the influence of the Institutional isomorphic pressures in the garments cluster and find what kind of institutional factors will force the adoption. 
The next section describes the theoretical background that supports this study. We then describe the framework and the methodology. We present the results of the data analysis in the next section. Further, in the next section we discuss the outcome of the study, the implications and set a future direction. In the final section, we conclude with a summary.

\section{Theoretical Background}

Clusters have been the interest of research and a focus to policy makers after Porter (1990) popularized the concept. Before Porter, it was studied as the concept of localization of industries as termed by Marshall as early as 1920 . A cluster is a geographically proximate group of interconnected companies and associated institutions in a particular field, linked by commonalities and complementary. The geographic scope of a cluster can range from a single city or state to a country or even a network of neighbouring countries (Porter, 1998). Giuliani (2005) refers to cluster as a geographical agglomeration of firms operating in the same industry. The relationship between the firm and the cluster is mutual. A cluster is defined and shaped by the contributions of the individual firm and the individual firm benefits by being a part of the cluster. A cluster obtains its competitive advantage primarily by it geographical proximity that helps the entire value system to coordinate better and provide more value. In addition, collective innovation, improvement and change are seen to be the major factor in creating the competitive advantage. Clusters are recognized for their productivity and innovation as compared to their counterparts outside the cluster.

\section{Institutional Isomorphic Pressures in a Cluster}

Arthur (1990) noted that a cluster would have the knowledge spill over that leads to a collective innovation arising from everyday contact and networking through geographical proximity, as well as from formal arrangements such as joint ventures and joint research work with the
Universities. This close relationship between the firm and others in the organisational environments within a cluster can be understood beyond the task environment of mere resource sharing to a close interdependence leading to an influence that shapes and sometimes controls the behaviour of the firm. Meyer and Rowan (1977) and DiMaggio and Powell (1983) in their institutional theories propose that isomorphism is the master bridging process within the cluster that makes organizations homogenous and more similar in structure overtime. DiMaggio and Powell highlight the influence as the social forces that lead to the copying of innovative practices among the firms and move towards an institutional isomorphism. They identify three general mechanisms of isomorphism: Coercive isomorphism in which an organization is compelled to adopt structures or rules, Mimetic isomorphism in which organizations tend to imitate other successful organizations when they are faced with uncertainty and ambiguity; and wherein normative isomorphism occurs when the organization adopts certain reforms because of professional pressure. The similarities caused by these three processes allow firms to interact with each other more easily and to build legitimacy among organizations.

Li Chao and Wang Xiaofei (2009) studied the role of isomorphism in the high-tech enterprise cluster of software industry in Zhongguancun, in China. They put forth the institutional theory from the view of sociology of organization and take the "Organizational Field" to explain the mechanism of isomorphism in enterprise cluster innovation, including coercive, mimic and normative isomorphism. They found that the innovative community in the organizational field makes enterprises in the cluster more and more homogeneous in innovation, and ultimately drives the escalation of high-tech parks.

Gabbay et al., (2001) argue that the industrial cluster has both social and geographic features. They find that the meaning of an "industrial cluster" is 
extended to provide a "facilitating proximity." and the firms will be capable of adopting relevant business attitudes. They argue that the purpose of this adoption is twofold that can be assumed from the institutional theory. The first is obtaining a "mental model" which serves as a corporate "steering mechanism" under uncertainty. The second is achieving legitimacy among other significant players in the "industrial cluster." Strand and Meyer (1994) studied the role of isomorphism in diffusion of innovation and suggested that institutional conditions operating in wider social systems affect the rate and form of diffusion. Rusten and Bryson (2007) support that the adoption of an ICT system by a firm, or by the supply chain or even by a cluster of firms may represent a form of DiMaggio and Powell's isomorphism in which firms are forced or encouraged to copy the behaviour of others. A firm because of all the three types of isomorphism may adopt ICT. In a supply chain, ICT adoption may be the result of coercion, as the firm may have to adopt a common ICT platform. In this case, the dominant firm determines the ICT investment decisions of other firms involved in the supply chain. Rusten and Bryson argue that the role of ICT in contributing to the factors that have been identified as being important for the foundation and functioning of industrial clusters. The discussion also explores the wider role that ICT plays within a cluster. It is a common misconception that ICT implies the end of geography or the importance of space as it has the ability to overcome the constraints imposed by distance (Cairncross, 1997). Clustered firms may have different adoption experiences compared to the firms located in other geographical settings.

In a similar concept, innovative technologies such as ERP is diffused by isomorphic pressure that drives a stronger urge of homogenization of managerial practices that are embedded in ERP systems as "best practice"-standards. Caldas and Wood (1999) found evidence for number different types of isomorphic forces in a study. They found that primary diffusion agents such as vendors, consultants and secondary diffusion agents such as media, management gurus and business schools and training agents produce a combined influence and generate a strong isomorphic pressure that pushes each organization to comply with institutionalized management practices. Teo et al., (2003) used institutional theory as a lens to understand the factors that enable the adoption of inter-organisational systems. They found that all the three institutional pressures - mimetic, coercive and normative pressures significantly influenced the adoption intention. This study recommends the application of institutional theory within Roger's (1995) framework to build a predictive model for adoption of information technologies.

Benders et al., (2006) studied on how and to what extent homogenization coincides with the deployment of ERP-systems. Using the work of DiMaggio and Powell on isomorphic pressures, they argue that the use of ERP-systems may in several ways, lead to standardization within and between the organizations. Competitive and institutional pressures play a role in ERPadoption. They also introduce a novel form of isomorphism called technical isomorphism. This plays a role in ERPimplementation and manifests itself in the enactment of blueprints for centralization and standard working procedures that are embedded in the ERP-software.

Liang et al., (2007) explain how the institutional theory that forces the organization to adopt ERP is mediated by the top management and encourages towards the assimilation in the post implementation stage. They identify that coercive pressure and mimetic pressure have influence on the top management, which affect the degree of ERP usage. They find that the normative pressure is not mediated by top management participation, but has a direct influence on ERP usage. They conclude that the institutional pressure is not only important for adoption and implementation, but also contributes to post implementation assimilation. Similarly, Baptista, et al., (2010) studied the positive impacts of the institutionalisation of IT in both adoption 
and assimilation. Poba-Nzaou et al., (2008) discuss on the applicable theories for ERP adoption specifically by SME's. They argue that SME's differ from large firms in the adoption of new technologies because of their own characteristics and their dependence in the supply chain. They propose a three dimensional framework of ERP adoption that include the institutional theory, diffusion of innovation theory, complexity theory on one dimension and form of change and motor of change on the other dimensions. Rajendran and Elangovan (2012) identified that the response to institutional forces is not based on the mechanism of pressure such as mimetic, coercive or normative, rather was based on the sources of these pressures. They found that the customer pressure was more obliged than other sources of pressure.

\section{Absorptive Capacity}

Researchers argue that in addition to the external forces, the motive to adopt new technologies will also depend on the internal factors of the firm. One such internal factor is the absorptive capacity (Elbertsen et al., 2006; Kouki et al., 2007; Raymond and Uwizeyemungu, 2007). A great deal of studies on innovation diffusion and competitiveness identify absorptive capacity as a key contributor to a wide range of organisational outcomes (Van den Bosch et al., 2003). Studying the role of absorptive capacity in the adoption of new technologies is particularly relevant to SME's because their research and development activity is generally low. Absorptive capacity is "an ability to recognize the value of new information, assimilate it, and apply it to commercial ends" and "is largely a function of the level of prior related knowledge" (Cohen and Levinthal, 1990).

Although the absorptive capacity of a firm depends on the individual absorptive capacities of its members, organizational absorptive capacity is not the mere sum of the individual absorptive capacities, but cumulative (Cohen and Levinthal). Their organizational absorptive capacity refers not only to the acquisition or assimilation of information by an organization but also to the organization's ability to exploit it. In the same line the organisations absorptive capacity is collectively translated into the cluster's absorptive capacity. Giuliani (2005) argues that the dynamic growth of a cluster depends on the knowledge acquisition, exploitation and generation by localised firms. Srivardhana and Pawlowski (2007) studied the relationships between ERP-related knowledge impacts and potential/realized absorptive capacity for business process innovation. Similar to this, Sedera, and Gable (2010) demonstrate a large, significant, positive relationship between Knowledge Management Competence and Enterprise Systems Success. Suh and Kym (2001) found that the absorptive capacity explains $66 \%$ of knowledge acquisition, which includes prior expertise, prior experience in knowledge acquisition, communication mechanism, and conflict resolution mechanism. This establishes a direct link between the cluster, organisation and the employees' absorptive capacity.

\section{Knitwear Garment Cluster}

Tirupur is an important trade centre in India, which is famous for its knitted garment wears. It is situated near Coimbatore, which is known as the "Manchester of South India". Tirupur is a major source of Foreign Exchange for the country because of its exports. Tirupur knitwear garments cluster is a dynamic cluster with a high growth potential. The City has registered a consistent growth of around 30\% every consecutive year since 1988. The cluster faces a competition from the neighbouring countries in the post quota scenario, since the buyers abroad would have a wider range of choice. Critical strategies for the cluster manufacturers for export competitiveness will shorten lead times, reduce expensive inventories and evolve innovative ways to connect the entire value chain electronically from sourcing of fabrics and accessories for garment manufacturing, and integrating these to final sales. This would require the SME cluster players to develop business 
processes to implement and manage etechnologies efficiently in order to meet this situation.

The knitwear garment units mostly use legacy systems. Raw materials and finished goods are managed by some fabric procurement software, while accounting and financial management are handled by the popular accounting software "Tally". These applications do not have integrated solution and the other cannot share the data from one user. They also lack transparency and security. The organisations do not have a tool to track the status of the customer orders. This results in contradictions between the actual stock and the information available in the system ("Fashion Knits: Enhancing Efficiency", n.d.). The areas in which the ICT intervention is seen to be quite useful at the Tirupur cluster are production scheduling, capacity planning, order management, costing, resource planning, skill management, sampling, production and inventory management. Overall, according to Project Vikas's survey, it was found out that there were huge gaps in the use of ICT technology in some areas like merchandising, designing, supply chain management and customer relations ("Project Vikas", n.d.). This cluster seems to be more conscious about spending on ICT in keeping a watch on the quality standards, as on the source supplies of exporters from the standardised exports. The study also found that the people had limited knowledge on the latest technologies used like e-commerce, data warehousing etc. It was also found that there is a limited ICT "vision" for a proper integrated business ("Weaving Success with IT Adoption", n.d.).

The main players of the knitwear and apparel cluster of Tirupur are the manufacturers of knitwear products for export and the domestic market. These manufacturers are supported by subcontractors who provide services like dyeing, bleaching, stitching, embroidery, etc. The support and ancillary players in the cluster include machinery manufacturers, machinery import agents, accessory suppliers, yarn dealers and merchant buyers etc. The technical support institutions include Government training institutes, training institutes run in collaboration with the Association and private institutes for textile designing and management institutes. The financial support institutions include developmental and commercial banks that have a direct stake in the growth of the cluster. Local industry associations of knitwear manufacturers, exporters, dyers, knitters and printers also form a part of the cluster and play a major role in the development of industry. ("Cluster Ecosystem", n.d.). Elangovan (2012) presented the characteristics of the cluster institutional pressures in the Tirupur Knitwear garments Cluster

\section{Conceptual Model and Hypotheses}

From the review of literature, looking at the institutional structure, we understand that the industrial cluster can produce an isomorphic pressure on firms to be homogeneous. This isomorphic pressure is understood to force organizations to adopt a common innovative technology such as ERP. Recursively it can also be seen as the adoption of a common technology like ERP and isomorphic forces that produce homogeneity in turn helps the formation of the cluster. DiMaggio and Powell's (1983) identified three dimensions of institutional isomorphic pressures namely, coercive, mimetic and normative pressure.

Liang et al., (2007) quote DiMaggio and Powell and describe coercive pressure as "the formal and external pressures exerted upon them by other organizations upon which they are dependent, and the cultural expectations in the society within which the organizations function". Coercive pressure is identified as the regulations from the local government, the industry associations and as a solution because of the competitive conditions. Benders et al., (2006), in their study found additional factors such as the customer/buyers and suppliers of the firm forcing them to adopt similar technologies for a smooth coordination. They may specify the adoption of certain technology as a minimum prerequisite for transaction. 
Mimetic isomorphism arises when organizations face uncertainty or the goals are ambiguous or the technologies are difficult to understand. They respond to the situation by just mimicking actions of other organizations that are perceived to be legitimate or successful. Mimetic pressure arises when the firms look at their competitor and perceive that they have greatly benefited, looked up on better by others in the same industry or favourably considered by their suppliers and customers. Benders et al., (2006), include the influence of the media, consultants and experts or following a recent trend as some of the mimetic forces. Normative isomorphism is defined as "the collective struggle of members of an occupation to define the conditions and methods of their work, to control the production of the future member professionals, and to establish a cognitive base and legitimization for their occupational autonomy" (DiMaggio and Powell, 1983; Liang et al., 2007). The professionals and experts working for the firm compare the extent of use of technologies by their suppliers and customers and exert a pressure on the firm. These professionals are also influenced by the government's promotion encouraging the use of technology.

Ravichandran, Han and Hasan (2009) proved that these pressures are sometimes perceived based on the agents of pressure. The SME cluster of Knitwear garments that was taken for the study has a welldeveloped institutional structure. Rajendran and Elangovan (2012) in a research in the SME cluster of Knitwear garments identified that the pressures were perceived based on the agents of pressure and demonstrated that even under the Institutional isomorphic pressures, the likelihood of adopting a technology depends on the intervention of the firm's understanding about the benefits, challenges and the complexity of the business operations. Therefore, the adoption of the technology depends on the trade off between the requirements, pressures, benefits and challenges. At the same time the firms need to have the knowledge on how to apply it for the business purpose. Cohen and Levinth (1990) define these characteristics as the absorptive capacity. Zahra and George (2002) propose that absorptive capacity can be measured at different stages, one during the acquisition and assimilation and the other during transformation and exploitation. They define absorptive capacity that is measured during the initial stages of adoption as 'potential absorptive capacity'. Liang et al., (2007) tested the absorptive capacity as a moderating variable at the organisational level during the assimilation of ERP. The absorptive capacity is understood as the prior experience of the employees to handle similar technologies, the company's ability to provide adequate technical and training support to the employees and finding a source of help to solve the problems in using the technology. Hence, it is hypothesized that:

H1: Cluster Institutional Isomorphic pressures have a positive influence on ERP adoption.

H2: Absorptive capacity has a positive influence on ERP adoption.

Phang et al., (2008) studied the interrelated aspects of institutional theory, and organizational learning. Bharati and Chaudhury (2011) empirically studied the role of institutional factors as they are mediated by absorptive capacity in the assimilation of Web 2.0 technologies. Similar to this, we propose to test the absorptive capacity as mediating the cluster institutional isomorphic pressures towards the adoption of ERP to understand if the absorptive capacity supports the Cluster institutional isomorphic pressures and accelerates the ERP adoption (Fig 1). For the purpose of this research, we look at the ERP adoption as the status of having implemented ERP or not having implemented it or having no intention to adopt. Hence, it is hypothesized that:

H3: Cluster Institutional Isomorphic pressures have a positive influence on Absorptive Capacity 
H4: Absorptive capacity will mediate the influence of Cluster institutional isomorphic pressures on ERP adoption.

\section{Control Variables}

The characteristics of the organisations in a cluster and particularly SMEs are an important factor of ERP adoption. Extant of literature have found organisational size as significant factor in ERP adoption (Liang, Saraf, Hu, \& Xue, 2007; Pan \& Jang, 2008; Teo, Wei \& Bengasat, 2003). Buonanno et al., (2005) studied the influence of business complexity on ERP adoption, a composed factor of the organisational characteristics such as company size, the market area, part of an industrial group, having branch offices or units, and the degree of functional and process extension. To control the differences among the organisations of the cluster, the variables found in Buonanno et al.'s study are used as control variables.

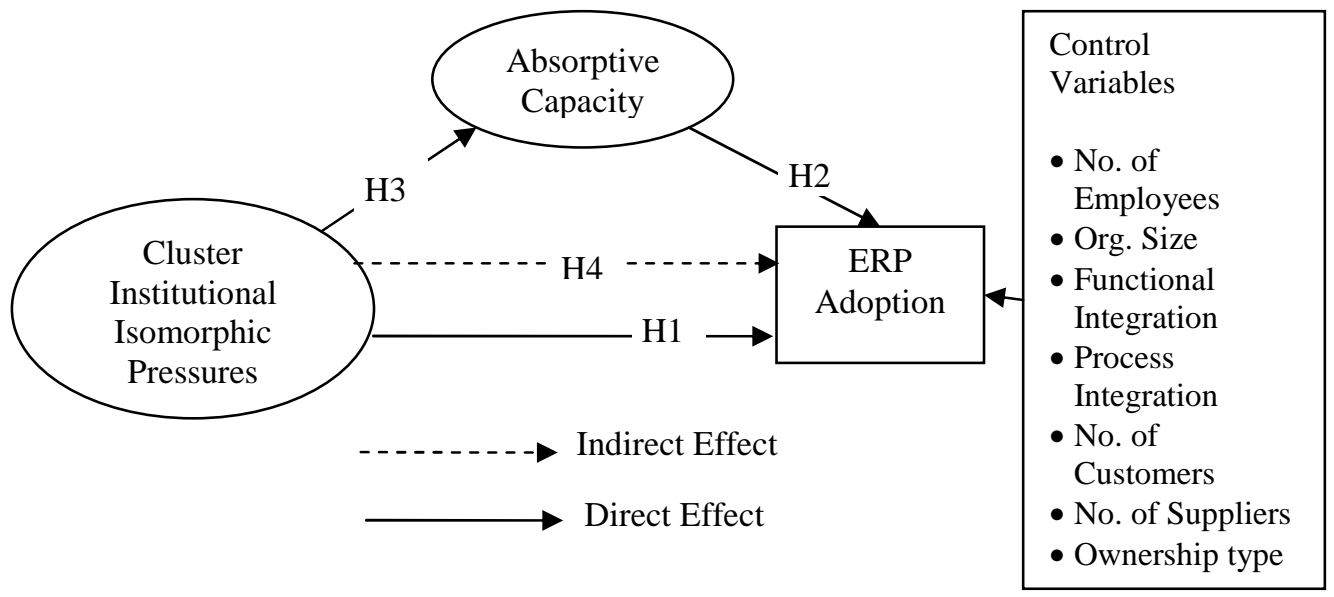

Figure 1: Conceptual research model on ERP adoption in Industrial Clusters

\section{Research Methodology}

To test the research question empirically, the following research design is formulated: An initial research framework is designed based on the literatures that were available. A survey method was used to test this framework. Based on the framework and the comprehensive literature review, a survey instrument was developed. The survey was conducted in the Tirupur knitwear cluster, the data was analyzed using Structural Equation Modelling (SEM) technique, and the results are interpreted.

The survey instrument was developed by adopting the items developed by Liang et al., (2007) to measure the DiMaggio and Powell's (1983) three basic types of institutional isomorphism; coercive, mimetic and normative pressures. We also include external pressures such as following the trend, Media influence and influence of consultants identified by Benders et al., (2006) under mimetic isomorphism. Explicit pressure from customer/client and supplier are added under coercive pressure. The absorptive capacity is measured on the items proposed by Liang et al., but we modify them to reflect more on the acquisition level. All the items are measured on a fivepoint agreeableness likert scale. The ERP adoption status is measured on sevenpoint scale that range from having no intention to adopt ERP to have been using ERP for over two years. This scale is developed by consolidating the measures used by Hung et al., (2004), Kamhawi (2008) and Teo et al., (2003). 
The Tirupur knitwear garments cluster is considered as the population of the study and the members of Tirupur Exporters' Association (TEA) and Apparel Export Promotion Council (AEPC) are considered as the sample framework. Within the sample framework, 1000 companies were randomly selected as the sample. We used the Dillman's (2007) tailored survey methodology. As a first step, we sent a communication to the sample companies introducing and explaining the objectives of the study and requesting them to support by participating in the survey. As a second step, a professionally printed questionnaire with a covering letter and postage prepaid business reply envelope was sent to the sample units. At the first instance, we received only 53 responses making only $5.3 \%$ response rate. Out of the 1000 questionnaires sent, 98 returned undelivered by the postal services. On scrutiny, we found that a few had changed their addresses and most of them had closed their business. However, information about them is still available on the database because they are the lifemembers of the association. As a policy the information of life-members are not removed with the hope that they may resume their operation any time. As a third step, we sent a reminder after 10 days of the initial mailing to the units who did not respond to the questionnaire. At the fourth stage, again a reminder with a replacement questionnaire was sent. We received another 86 responses after these two stages. In the final stage, we made a multiple mode direct contact and received 90 responses totalling 229 responses, making around $22.9 \%$ response rate. The data collected were entered on a spreadsheet, which was then cleaned and filtered. Three responses were found incomplete and unusable.

Table 1: Measurement items and their Scale

\begin{tabular}{|c|c|c|c|c|}
\hline Construct & $\begin{array}{c}\text { Sub } \\
\text { Constructs }\end{array}$ & Indicators & $\begin{array}{l}\text { Measurement } \\
\text { Scale }\end{array}$ & Source \\
\hline \multirow{5}{*}{$\begin{array}{l}\text { Cluster } \\
\text { Institutiona } \\
1 \\
\text { Isomorphic } \\
\text { Pressure }\end{array}$} & $\begin{array}{l}\text { Business } \\
\text { Services } \\
\text { Pressure }\end{array}$ & $\begin{array}{l}\text { Influence by Consultants and } \\
\text { Experts } \\
\text { Influenced by Media } \\
\text { Trade Association Encourages }\end{array}$ & \multirow{5}{*}{$\begin{array}{c}5 \text { Point } \\
\text { Agreeableness } \\
\text { Likert Scale }\end{array}$} & \multirow{5}{*}{$\begin{array}{l}\text { Liang et al., } \\
\text { (2007); } \\
\text { Benders, } \\
\text { Batenburg } \\
\text { and Blonk } \\
\text { (2006) }\end{array}$} \\
\hline & \begin{tabular}{|l|} 
Customer \\
Pressure
\end{tabular} & \begin{tabular}{|l} 
Firm's Customer Require ERP \\
Firm's Customer Adopted ERP
\end{tabular} & & \\
\hline & $\begin{array}{l}\text { Peer } \\
\text { Pressure }\end{array}$ & $\begin{array}{l}\text { Perception of Competitor's } \\
\text { Customers } \\
\text { Main competitors benefited } \\
\text { Industry perceive favourably } \\
\text { Required for competitiveness }\end{array}$ & & \\
\hline & $\begin{array}{l}\text { Supplier } \\
\text { Pressure }\end{array}$ & $\begin{array}{l}\text { Firm's Supplier Require ERP } \\
\text { Firm's Suppliers Adopted ERP } \\
\text { Follow Recent Trend } \\
\text { Perception of Competitor's } \\
\text { Supplier }\end{array}$ & & \\
\hline & \begin{tabular}{|l} 
Government \\
Pressure
\end{tabular} & $\begin{array}{l}\text { Government Promotion } \\
\text { Government Requires }\end{array}$ & & \\
\hline $\begin{array}{l}\text { Absorptive } \\
\text { capacity }\end{array}$ & - & $\begin{array}{l}\text { Able to provide training } \\
\text { Know who helps } \\
\text { Provide technical support } \\
\text { Employee's Prior Experience }\end{array}$ & $\begin{array}{l}5 \text { Point } \\
\text { Agreeableness } \\
\text { Likert Scale }\end{array}$ & $\begin{array}{l}\text { Liang et al., } \\
\text { (2007); }\end{array}$ \\
\hline
\end{tabular}




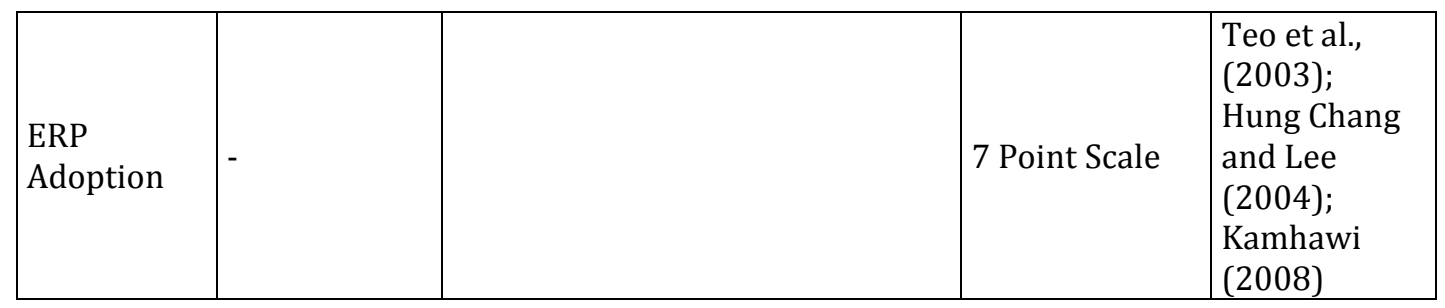

The data were prepared for data analysis. Since our research model proposes to measure the mediating effect, we decided to use AMOS (Analysis of Moment Structures) that implements covariance based Structural Equation Modelling (SEM). It helps in creating models to test hypotheses and confirm relationships among observed and latent variables. This software provides multivariate analysis including regression, factor analysis, correlation and analysis of variance and even extends beyond the standard methods to gain additional insight into causal models and explore the interaction effects and pathways between the variables. One of the most common uses of Structural Equation Modelling is the simultaneous estimation of direct and indirect effects. We use the direct and indirect effect analysis for testing the mediation in our model. The measurement model was first tested and then the structural model was analysed for the path coefficients and the goodness of fit.

\section{Data Analysis and Results}

The demography of the responding companies (Table 2) show that most of them (38.9\%) have the number of employees between 51 and 250 and the suppliers $(40.7 \%)$, the customers $(38.9 \%)$ in the range of 11 to 20 . The type of ownership of a larger portion (55.3\%) of the respondents is proprietorship. $91.6 \%$ of the respondents are small and medium size enterprises. We have included the portion of larger enterprises for comparison. Nearly $68.1 \%$ of the firms have not adopted ERP. Only $23.9 \%$ have adopted ERP and are in completion stage or using them already. Rests of the firms $(8 \%)$ are in the process of implementing. 
Table 2: Demographics of the responding companies

\begin{tabular}{|c|c|c|c|}
\hline Variable & Scale & Frequency $(\mathrm{N})$ & Percentage $(\%)$ \\
\hline \multirow{6}{*}{$\begin{array}{l}\text { Number of } \\
\text { Employees }\end{array}$} & $1-10$ & 22 & 9.7 \\
\hline & $11-50$ & 83 & 36.7 \\
\hline & $51-250$ & 88 & 38.9 \\
\hline & $251-500$ & 20 & 8.8 \\
\hline & $501-1000$ & 9 & 4.0 \\
\hline & $>1000$ & 4 & 1.8 \\
\hline \multirow{3}{*}{ Organisation Size } & Small & 104 & 46.0 \\
\hline & Medium & 103 & 45.6 \\
\hline & Large & 19 & 8.4 \\
\hline \multirow{5}{*}{$\begin{array}{l}\text { Type of } \\
\text { Ownership }\end{array}$} & Proprietor & 125 & 55.3 \\
\hline & Partnership & 81 & 35.8 \\
\hline & Private Ltd & 18 & 8.0 \\
\hline & Public Ltd & 1 & .4 \\
\hline & Joint Venture & 1 & .4 \\
\hline \multirow{5}{*}{ No. of Suppliers } & $<10$ & 45 & 19.9 \\
\hline & $11-20$ & 92 & 40.7 \\
\hline & $21-50$ & 68 & 30.1 \\
\hline & $51-100$ & 11 & 4.9 \\
\hline & $>100$ & 10 & 4.4 \\
\hline \multirow{5}{*}{ No. of Customers } & $<10$ & 87 & 38.5 \\
\hline & $11-20$ & 88 & 38.9 \\
\hline & $21-50$ & 43 & 19.0 \\
\hline & $51-100$ & 3 & 1.3 \\
\hline & $>100$ & 5 & 2.2 \\
\hline \multirow{7}{*}{$\begin{array}{l}\text { ERP Adoption } \\
\text { Status }\end{array}$} & No intention to adopt & 34 & 15.0 \\
\hline & Consider in future & 61 & 27.0 \\
\hline & Considering some modules & 28 & 12.4 \\
\hline & Planning first project & 31 & 13.7 \\
\hline & Configuration and implementing & 18 & 8.0 \\
\hline & Completed Implementation & 24 & 10.6 \\
\hline & Already in use for more than 2 Years & 30 & 13.3 \\
\hline
\end{tabular}

\section{Testing the Measurement Model}

Structural Equation Modelling (SEM) technique uses factor analysis and regression analysis and test the fitness of the model to the data. SEM analysis is done in two stages. First, the measurement model is measure the validity of the measures through a confirmatory factor analysis. Second, the structure of the model is tested for each of its path to find the causal influence. The constructs measured by multiple items are tested for unidimensionality, convergent validity, internal consistency, and discriminant validity. For this purpose, we first developed the measurement model of latent constructs: Absorptive capacity, Business Services Pressure, Customer
Pressure, Peer Pressure, Supplier Pressure and Government Pressure and performed the Confirmative factor analysis. Confirmatory factor analysis (CFA) is a multivariate statistical procedure that is used to test how well the measured variables consistently represent the constructs that are understood by a researcher. The primary objective of a CFA is to determine the ability of a predefined factor model to an observed set of data. The most commonly used test of model adequacy is the chi-square goodness of fit test. The null hypothesis for this test is that the model adequately accounts for the data, while the alternative is that there is a significant amount of discrepancy. This technique is found appropriate for smaller sample because this test is highly sensitive 
to the size of the sample, such that the tests involving large samples will generally lead to a rejection of the null hypothesis.

We use the following goodness-of-fit indices for assessing the degree of fit between the model and the sample: Chi Square $\left(\chi^{2}\right)$, Tucker Lewis Index (TLI), considering a value above 0.90 as acceptable and above 0.95 as excellent
(Tucker and Lewis, 1973), the Comparative Fit Index (CFI), considering a value above 0.90 as acceptable and above 0.95 as excellent (Bentler, 1990; Bentler and Bonett, 1980), and Root Mean Square error of approximation (RMSEA) with less than 0.08 being acceptable and less than 0.05 being excellent (Browne and Cudeck, 1993). The results in Table 3 show that items loaded on to five components.

Table 3: Results of the measurement model of Institutional isomorphic pressures

\begin{tabular}{|c|c|c|c|c|c|c|c|c|c|c|c|c|}
\hline & & & & & & & B & & S.E. & C.R. & $\mathrm{P}$ & Beta \\
\hline Influence & $\mathrm{y}_{\mathrm{Co}}$ & ulta & and Experts & Busines & ervices $\mathrm{Pr}$ & ssure & & 1 & & & & 0.874 \\
\hline Influenced & by $\mathrm{N}$ & dia & usiness Serv & Pressu & & & 1.1 & & 0.068 & 16.852 & $* * *$ & 0.898 \\
\hline Trade Ass & ciati & En & rages $\leftarrow$ Bus & ss Servi & Pressure & & 0.9 & & 0.068 & 14.473 & $* * *$ & 0.799 \\
\hline Firm's Cus & ome & equ & $\mathrm{ERP} \leftarrow \mathrm{Cus}$ & er Press & & & & 1 & & & & 0.738 \\
\hline Firm's Cu & ome & dol & $\mathrm{ERP} \leftarrow \mathrm{Cu}$ & ner Pres & & & 1.1 & & 0.13 & 8.575 & $* * *$ & 0.706 \\
\hline Perception & of $\mathrm{C}$ & ipet & 's Customer & Peer $\mathrm{Pr}$ & & & & 1 & & & & 0.895 \\
\hline Main com & etito & ben & ed $\leftarrow$ Peer $\mathrm{P}$ & ure & & & 0.9 & & 0.06 & 16.117 & $* * *$ & 0.860 \\
\hline Industry $\mathrm{p}$ & rcei & favo & ably $\leftarrow$ Peer & sure & & & 0.9 & & 0.077 & 12.292 & $* * *$ & 0.714 \\
\hline Required & or co & etit & ness $\leftarrow$ Peer & ssure & & & 0.8 & & 0.064 & 12.87 & $* * *$ & 0.737 \\
\hline Firm's Sup & plier & equi & $\mathrm{ERP} \leftarrow \mathrm{Supp}$ & Pressur & & & & 1 & & & & 0.759 \\
\hline Firm's Sup & pliers & dop & $\mathrm{ERP} \leftarrow \mathrm{Su}$ & r Pressi & & & 1.1 & & 0.132 & 8.667 & $* * *$ & 0.847 \\
\hline Follow Re & tent & and & Supplier Pre & & & & 0.6 & & 0.086 & 7.388 & $* * *$ & 0.554 \\
\hline Perception & of $\mathrm{C}$ & ipet & 's Supplier & upplier I & sure & & 0.2 & & 0.074 & 3.509 & $* * *$ & 0.261 \\
\hline Governme & t $\operatorname{Pr}$ & atic & $\leftarrow$ Governme & ressure & & & & 1 & & & & 0.828 \\
\hline Governme & at $\mathrm{Re}$ & ires & Governmen & essure & & & 0.8 & & 0.171 & 5.022 & $* * *$ & 0.740 \\
\hline CMIN & DF & $\mathrm{P}$ & CMIN/DF & TLI & CFI & RMS & & & 90 & HI 90 & & OSE \\
\hline 241.148 & 80 & 0 & 3.014 & 0.86 & 0.894 & 0.09 & & & 082 & 0.109 & & 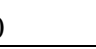 \\
\hline
\end{tabular}

The constructs are theoretically justified because the findings correlate to the argument of Benders et al., (2006) quoting DiMaggio and Powell that the isomorphic forces are distinguishable analytically but not necessarily empirical. They state that the forces often act in conjunction. Government forces are translated into norms through legislation and legal enforcement and may reflect in normative forces on which decision makers try to comply. Ravichandran, Han and Hasan (2009) examined the institutional pressures on IT investment from the perspectives of the institutional agents namely, industry peers, trading partners
(Customers and Suppliers) and the shareholders.

\section{Testing the structural model}

After obtaining an acceptable fit of the items in the measurement model, a complete structural model is developed. The causal steps methods developed by Baron and Kenny (1986) is the most commonly used and most frequently cited test of mediation. However, the causal steps approach of Baron and Kenny has been criticized for various reasons. In spite of the criticism, this method is widely used because it is simple and easy to understand and interpret (Hayes, 2009). As an 
alternative, researchers recommend an approach based on product of coefficients, most well known as the Sobel test. Hayes compares different techniques and proposes that among the alternatives, bootstrapping and the empirical $M$-test seems to win the battle. He also suggests that SEM software such as AMOS has implemented the indirect effect and bootstrapping technique that can be used effectively.

Bootstrapping is a way to overcome the limitations on assumptions of normality. Bootstrapping is a resampling and replacement method that generates the required number of samples of a desired size by mimicking the original sampling process and drawing cases from the original sample. Typically the number of bootstrapped sample will be as large as 1000 or more. Hayes (2009) explains the analysis of indirect effect and validation using bootstrapping technique. Once a resample is constructed, the path coefficient from independent variable (IV) to moderator (M) and from Moderator (M) to Dependent variable or Outcome variable (DV) is calculated from the resample data set and the product of the path coefficients is recorded. This process is repeated to the number of bootstrapped samples.

After the values of indirect effect are calculated as the product of path coefficients for all the bootstrapped samples, a distribution is obtained to generate a confidence interval (CI \%). In the distribution, the lower bound and the upper bound value of the estimate at the $95 \%$ confidence interval is found. If zero is not between the lower and upper bound estimate, then we can say that the indirect effect is not zero with the given percentage of confidence level (typically 95\%). This is conceptually similar to rejecting the null hypothesis that the true indirect effect is zero. We propose to use this analysis technique for our study. Before performing the bootstrapping analysis for indirect effect, we first establish the relationship between the test variables in the structural model. We find that the structural model fits well only when one item from supplier pressure (perception of the competitor's supplier) that loaded and both the items that formed the construct of Government Pressure are removed.

The effect of Cluster institutional isomorphic Pressures (IV) on ERP adoption (DV) is calculated and the results are presented in table 5. The relationship is also found to be positive and statistically significant $(\mathrm{B}=2.074, \mathrm{C} . \mathrm{R} .=7.743 \mathrm{P}<$ $0.001)$. The test of goodness of fit of the model reveals that CFI $(0.925)$, TLI $(0.904)$ and RMSEA $(0.088, \mathrm{P}<0.001$ at $90 \% \mathrm{CI})$ values show a good fit. We find that the CMIN/DF value to be 2.727 at $\mathrm{P}<0.001$. Arbuckle (2009) quotes certain authors and recommends even ratios as low as 2 or as high as 5 to indicate a reasonable fit. Therefore we consider the model to have an adequate fit. This supports the hypothesis $\mathrm{H} 1$ that Institutional isomorphic pressures have a positive influence on ERP adoption.

Table 4: Effect of Cluster Institutional isomorphic pressures on ERP Adoption

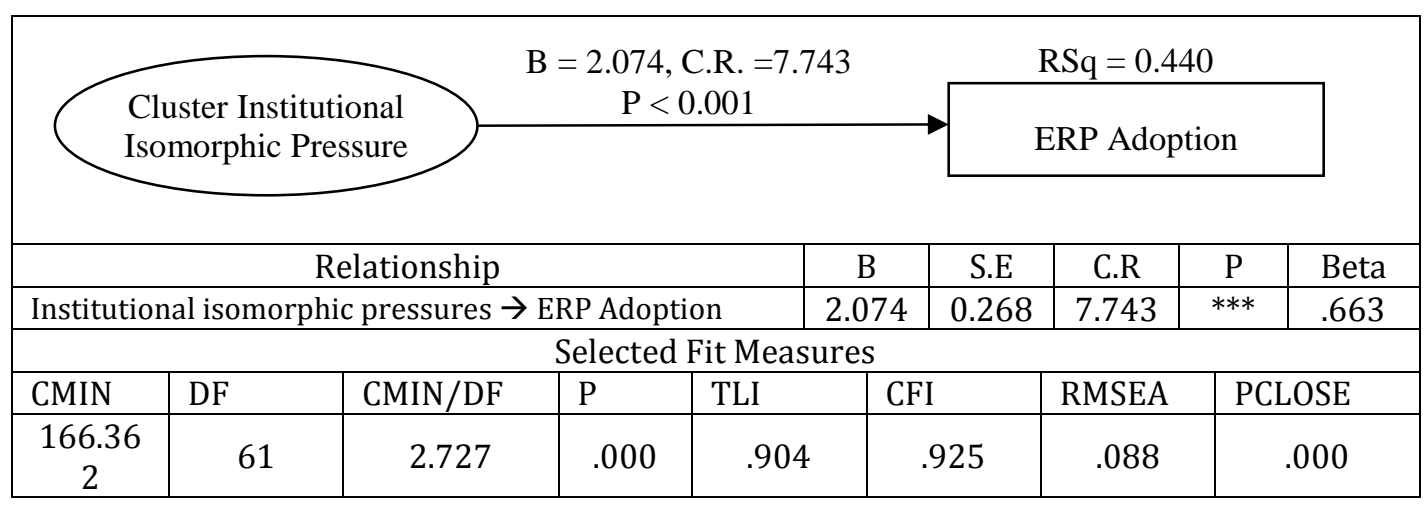


The test of goodness of fit of the model reveals that the CFI (0.985), TLI (0.971) values show a very good fit. RMSEA is found to be $0.085, \mathrm{P}=0.128$ at $90 \% \mathrm{CI}$. The RMSEA was less than the 0.1 cut-off value as suggested by Browne and Cudeck (1993), and close to 0.08, which is recommended as reasonable. However, the $\mathrm{p}$-value for testing the null hypothesis that the population RMSEA is no greater than 0.05 is insignificant at $\mathrm{P}=0.128$. Browne and Cudeck suggest that a RMSEA of 0.05 or less indicates a close fit.
Employing this definition of close fit, PCLOSE gives a test of close fit while $\mathrm{P}$ gives a test of exact fit (Arbuckle, 2009). Therefore we interpret that the model has a reasonable fit but it is statistically insignificant. Similarly CMIN/DF (2.125) is above two but less than 3 which again can be considered to be reasonably fit. Overall we may consider that model has an adequate fit. This supports the hypothesis $\mathrm{H} 2$ that absorptive capacity has a positive influence on ERP adoption.

Table 5: Effect of Absorptive Capacity on ERP Adoption

\begin{tabular}{|c|c|c|c|c|c|c|c|c|}
\hline & \multicolumn{4}{|c|}{$\begin{array}{c}\mathrm{B}=2.070, \mathrm{C} . \mathrm{R} .=9.707 \\
\mathrm{P}=0.000\end{array}$} & \multicolumn{4}{|c|}{ ERP Adoption } \\
\hline \multicolumn{3}{|c|}{ Relationship } & $\mathrm{B}$ & S.E & & C.R & $\mathrm{P}$ & Beta \\
\hline \multicolumn{3}{|c|}{ Absorptive Capacity $\rightarrow$ ERP Adoption } & .070 & .213 & & 9.707 & $* * *$ & .744 \\
\hline \multicolumn{9}{|c|}{ Selected Fit Measures } \\
\hline CMIN & $\mathrm{DF}$ & CMIN/DF & \multicolumn{2}{|c|}{ TLI } & $\mathrm{CFI}$ & & RMSEA & PCLOSE \\
\hline 13.012 & 5 & 2.602 & \multicolumn{2}{|c|}{.971} & .985 & & .085 & .128 \\
\hline
\end{tabular}

The test between institutional isomorphism (IV) and the absorptive capacity (M) is done and the results are presented in table 6 . The critical ratio $(\mathrm{CR}=3.953)$ of unstandardised regression estimate $(B=1.560)$ is significant at $\mathrm{p}<0.001$, which means that Institutional isomorphic pressures has a positive and significant effect on Absorptive capacity. The test of goodness of fit of the model reveals the relative fit indices CFI (0.937),
TLI (0.924) and RMSEA (0.071, $\mathrm{P}<0.005$ at $90 \%$ CI) values show a good fit. The overall fit index, CMIN/DF (2.125) at $p<0.001$ is above two. As discussed in the previous paragraphs, we consider the model to have a sufficient fit. This supports the hypothesis H3 that Institutional isomorphic pressures have a positive influence on absorptive capacity.

Table 6: Effect of Cluster Institutional isomorphic pressures on Absorptive capacity

\begin{tabular}{|c|c|c|c|c|c|c|}
\hline \begin{tabular}{|l} 
Cluster Institutional \\
Isomorphic Pressures
\end{tabular} \\
\hline \multicolumn{7}{|c|}{$\begin{array}{c}\text { B }=1.560, \text { C.R. }=3.953 \\
\mathrm{P}=0.000\end{array}$} \\
\hline Relationship
\end{tabular}


Having established the relationship between each variable in the model, we now consider the evaluation of the indirect effect. In the 'analysis properties' of AMOS, we selected the 'Indirect, direct and total effects' analysis in the output menu and chose a maximum likelihood bootstrapping of 5000 samples, and considered a 95\% confidence interval in calculating the lower bound and upper bound values of the indirect effect estimation. The results are presented in the table 8 . The model depicts the interrelationship between the Institutional isomorphic pressures (IV), Absorptive capacity (M) and the ERP adoption (DV). The un-standardised estimate of all the direct relationship are positive and their critical ratios are statistically significant at $\mathrm{P}<0.001$. The goodness of fit of the model is analysed and the relative fit indices TLI, CFI and GFI are found to be $0.936,0.948$ and 0.907 respectively. The RMSEA is found as 0.066 at PClose less than 0.05. The RMR value is found to be 0.085 . All these values show a good fit of the model. The overall model fit of CMIN (190.401) to the degree of freedom (97) is found to be 1.963 at $\mathrm{P}<0.001$, which again shows to be a considerably good fit.

Table 7: Mediating effect of Absorptive Capacity between Cluster's Institutional isomorphic pressures and ERP adoption

\begin{tabular}{|c|c|c|c|c|c|c|c|c|c|c|c|}
\hline \multicolumn{7}{|c|}{ Direct Effect } & $\mathrm{B}$ & S.E & C.R & $\mathrm{P}$ & Beta \\
\hline \multicolumn{7}{|c|}{$\begin{array}{l}\text { Cluster Institutional isomorphic pressures } \rightarrow \text { Absorptive } \\
\text { Capacity }\end{array}$} & 1.481 & 0.36 & 4.111 & $* * *$ & .538 \\
\hline \multicolumn{7}{|c|}{ Absorptive Capacity $\rightarrow$ ERP Adoption } & 1.429 & 0.198 & 7.22 & $* * *$ & .537 \\
\hline \multicolumn{7}{|c|}{$\begin{array}{l}\text { Cluster Institutional isomorphic pressures } \rightarrow \text { ERP } \\
\text { Adoption }\end{array}$} & 2.498 & 0.666 & 3.751 & $* * *$ & .341 \\
\hline \multicolumn{7}{|c|}{ Organisation Size $\rightarrow$ ERP Adoption } & 0.299 & 0.142 & 2.102 & 0.036 & 0.098 \\
\hline \multicolumn{7}{|c|}{ Number of Customers $\rightarrow$ ERP Adoption } & 0.252 & 0.1 & 2.516 & 0.012 & 0.117 \\
\hline \multicolumn{12}{|c|}{ Selected Fit Measures } \\
\hline CMIN & DF & CMIN/DF & $\mathrm{P}$ & TLI & CFI & GFI & \multicolumn{2}{|c|}{ RMR } & RMSEA & \multicolumn{2}{|c|}{ PCLOSE } \\
\hline 190.401 & 97 & 1.963 & .000 & .936 & 0.948 & 0.907 & \multicolumn{2}{|c|}{0.085} & .066 & \multicolumn{2}{|c|}{.031} \\
\hline
\end{tabular}

Test for Mediation - Indirect effect

\begin{tabular}{|c|c|c|}
\hline Indirect Effect & B & Beta \\
\hline Cluster Institutional isomorphic pressures $\rightarrow$ ERP Adoption & 2.117 & .289 \\
\hline Total Effect & B & Beta \\
\hline Cluster Institutional isomorphic pressures $\rightarrow$ ERP Adoption & 4.615 & .63 \\
\hline
\end{tabular}

Test for significance of Indirect Effect

\begin{tabular}{|c|c|c|c|c|c|}
\hline \multicolumn{6}{|c|}{ (Number of Bootstrap samples = 5000 and Bias corrected confidence Interval = 95\%) } \\
\hline $\begin{array}{c}\text { Cluster Institutional isomorphic pressures } \\
\rightarrow \text { ERP Adoption }\end{array}$ & $\begin{array}{c}\text { ML } \\
\text { Estimate }\end{array}$ & BS SE & $\begin{array}{l}\text { LB } 95 \\
\text { CI }\end{array}$ & $\begin{array}{l}\text { UB } 95 \\
\text { CI }\end{array}$ & $\mathrm{P}$ \\
\hline Total Effect & 4.615 & 1.362 & 3.086 & 7.838 & .001 \\
\hline Direct Effect & 2.498 & 0.845 & 1.199 & 4.33 & .001 \\
\hline Indirect Effect & 2.117 & 0.866 & 1.257 & 4.599 & .000 \\
\hline
\end{tabular}

The test for mediation reveals the direct effect of Institutional isomorphic pressures on ERP adoption $(B=2.498)$ in the presence of absorptive capacity as the mediating variable is positive and statistically significant $\quad(\mathrm{CR}=3.751, \quad \mathrm{P}<0.001)$. The 
indirect effect of Cluster Institutional isomorphic pressures on ERP adoption mediated by absorptive capacity is also positive with an unstandardised coefficient value of $B=2.117$. The total effect of both the Cluster Institutional isomorphic pressures and the absorptive capacity on the ERP adoption is found to be positive $(B=4.615)$. To evaluate the significance of the indirect effect, we look at the estimates of the bootstrapping. The mediating effect measured as the indirect effect is found to lie between the lower bound value (1.257) and the upper bound value (4.599) of the bootstrapped samples. This range is identified as a statistically significant $(\mathrm{P}<$ 0.001) non-zero range. Therefore, we interpret that indirect effect, being zero by chance can be rejected. This supports the hypothesis $\mathrm{H} 4$ that absorptive capacity will mediate the influence of Cluster Institutional isomorphic pressures on ERP adoption.
Considering the control variables included in the model, only organisation size and number of customers has an influence. Other variables were found to be insignificant. In addition, to remove the bias of the control variables, the model was tested excluding them. The sign and significance of the paths were found to be the same. Having found that the individual path of relation between the variables and the indirect effect are all positive and significant, we interpret that the mediating effect is complementary to the direct effect or in other words, the relationship can be seen as partially mediated. Finally, we look at the degree of the effect of these variables on ERP adoption by analysing the RSq value. We find that the $R S q=0.631$ meaning that the Cluster Institutional isomorphism mediated by absorptive capacity explains $63.1 \%$ of the variation in the ERP adoption (Fig 2).

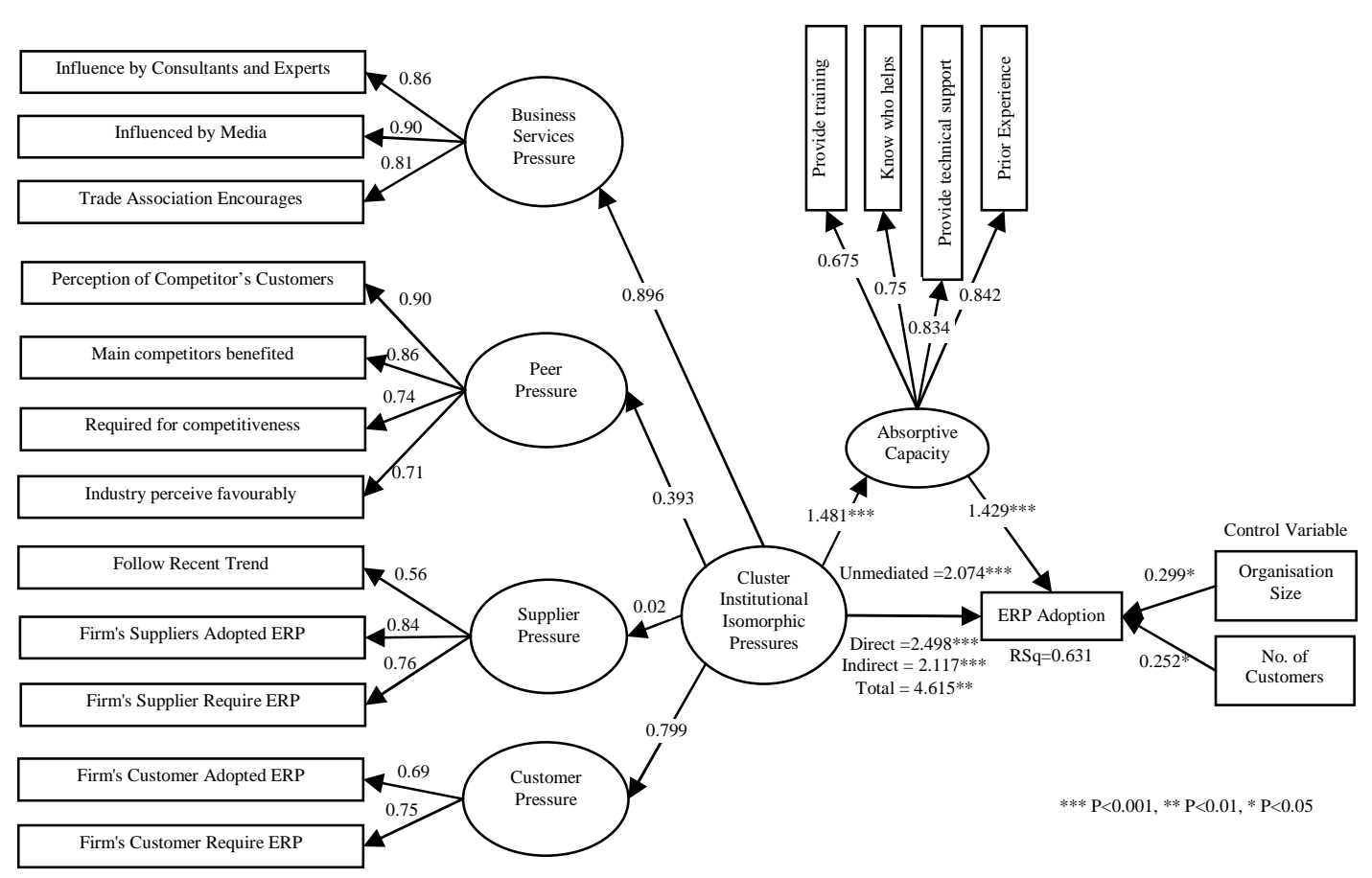

Figure 2: Structural model with path coefficients

\section{Discussion}

This study is designed to test empirically the influence of the Cluster Institutional isomorphic pressure that motivates the adoption of ERP system in the knitwear garments cluster. We proposed to examine this relation because a matured cluster 
such as the one taken for this study too has a slower and lower adoption of ERP. We assumed that the pressure generated by the Cluster Institutional isomorphism, depending up on the firm's capacity to absorb new technology, might be differently translated into a driving force towards the ERP adoption. The need of ERP for this cluster can be understood from the various processes involved in the end product and how the firms have integrated them. Along with the complexity of operation, the competitive pressure from the neighbouring countries requires the firms of the cluster to be more effective. The review of literature explains the strong institutional structure of the cluster. Many of the organisations are involved in the initiatives of ICT and exert pressure on the members of the cluster. However, the

entrepreneurship movement identified in this cluster is a transition from mostly agrarian (Chari, 2000) and there is always a shortage of employees at the production and the administrative levels. Therefore, there is a need to understand the role of absorptive role of the organisation that can readily translate the isomorphic pressure into true homogenous structure for the cluster to be collectively competitive.

DiMaggio and Powell (1983) state that the forces often act in conjunction, therefore we proposed to test the influence of the isomorphic pressure collectively on the ERP adoption. The Cluster Institutional isomorphic pressure was explained by the Business Services Pressure, customer pressure, and the peer pressure more prominently. Whereas the supplier pressure, though positive, did not have a high impact and government pressure is found to be insignificant. The Cluster Institutional isomorphic pressure together is found to increase the ERP adoption. This does prove the earlier studies of Teo et al., (2003). The study finds that business service agencies such as consultants, media and the trade association produce greater isomorphic pressures. This can be attributed to the focus of the business development agencies such as UNIDO and initiatives such as Project Vikas are playing an important role in the growth of the cluster. In addition, the exporters' association is recognised for its active role in many collective initiatives and in particular, e-business support, it provides to the firms in the cluster. This kind of pressures may be unique to the industrial clusters because of its concentration and drive towards homogenisation.

The study finds that the pressures from the customer is both mimetic and coercive and provide reasons for the firms to adopt ERP. The cluster mainly operates on made-toorder production system, where the customers are mostly importers from the Europe and the United States. The International buyers (Customers) specify their design requirements for the product and demand the legal compliances on various aspects as per the laws of the land. Certain buyers insist on business process and documentation to make their transaction convenient. The buyers, to track the progress of their orders, recommend the firms to install particular software as small and economic to as sophisticated as ERP to be connected with their own system through electronic data interchange (EDI). The pressure from such buyers is obliged by the firms for a continued business and adopts them at any cost. Katharina, Sabine and Fiona (2009) compare regulatory pressure to coercive pressure and argue that it affects firms stronger than other institutional pressure.

However, with regard to the suppliers, the firm takes a superior position by providing business to them and does not feel it a pressure from them. This coincide with the findings of Kouki et al., (2007), who studied the Institutional isomorphic pressures on ERP assimilation in a manufacturing food company, which had a similar kind of customer and supplier pressure. Premkumar (2003) argues that even small firms may adopt technologies if the suppliers insist on using advanced technologies for doing business with them. However, this study fails to prove this and the supplier pressure was found to be insignificant. Premkumar (2003) argues that gaining competitive advantage is an 
important motivation for technology implementation. However, this study focuses on the Institutional isomorphism in which the competitor pressure is understood as a peer pressure. Rather competing for resources the peer pressure explains the need for political power and status. In addition, the competitor pressure is not significant or felt seriously in this cluster. This is due to the close network of the organizations being developed from the same community and enough scope left to each businesses. The interviews with the respondents reveal that the industry does not feel a competition within them. There were instances quoted by the respondents that because of the capacity constraints they serve only a few buyers and sometimes drop a buyer when there is constant support from another buyer.

However, the peer pressure because of the institutional structures in the cluster is found to produce a drive towards obtaining status by adoption of sophisticated technologies. Caldas and Wood Jr (2000) explain this as the managerial fads and fashions that have high level of emotional content. Craig Standing, Ian Sims, Peter Love (2009) found that government agencies by its layers of authority influenced the adoption or rejection of technology and such forces varied in their influence over time. They proposed the notion of patterns of conformity and nonconformity that recognise the changes in levels of compliance over time as organizational forces arise. The government pressures are disseminated through many layer of the institutional setup. The study also finds that the initiatives of the government promotes the adoption of ERP but does not mandate the use of it. The initiatives such as Technology Upgradation Fund Scheme (TUFS) introduced by the Ministry of Textiles (MOT), is intended to facilitate induction of state-of-the-art or near state-of-the-art technology. The Project Vikas, a joint initiative of National Manufacturing Competitiveness Council (NMCC) Government of India and MICROSOFT, AEPC and Textile committee are also found active in promoting ICT adoption ("Project Vikas", n.d.). Despite their efforts, the pressure is rarely felt by the firms. The cluster utilises the services of the management consultants in industrial engineering, compliances and audit of quality management systems etc. The consultants along with these roles play a role in recommending the use of information technology. The pressures from these consultants are mildly felt by the firm in a need to improve quality, productivity and compliance. The exposure of the cluster to the media through commercials and trade fairs has made them aware of the technologies. The cluster hosts a series of events and world-class trade fairs in knitwear technology and related areas. Vendors exhibit their latest technology and induce the firms to follow latest trends. The role of the trade association is prominently felt. The exporters association and various other associations are all collectively involved in the promotion of the ERP adoption. The ereadiness centre is one such initiative for ICT and a special purpose vehicle (SPV) operates especially for the ERP adoption. The pressure for homogeneity that arises out of comparing with similar firms, who have adopted the technology, though not competing, is seen evident in the study. The perception of the customers on the firms adopted ERP and how these firms are looked up on by others in the same cluster can be seen as envy and has a substantial influence on other firms to adopt ERP.

As noted in the literature, the maturity of the knitwear cluster is clearly reflected in the absorptive capacity of the firms. They are ready to provide adequate support to acquire and implement the technology. This shows that the attitude of the top-level management is positive towards the adoption of ERP. The earlier studies have found that the firms use ICT to some extent, but are slower in adopting an integrated technology like ERP. This indicates that the employees have experience in using computers and that will make the ERP adoption easier. As there is a close institutional network in the cluster, the firms have understood and are aware of who will provide the support for solving the issues related to ERP. The firms are also positive in providing training to 
the employees. Thus, the study highlights that the firms have an adequate absorptive capacity to adopt and exploit ERP. The need of absorptive capacity in adoption of technology has been already studied and this study verifies that the there is a positive influence of absorptive capacity that can lead to adoption of ERP.

The readiness to adopt ERP can also be understood to have been created by the isomorphism. The study shows that the Cluster Institutional isomorphism positively influences the absorptive capacity. The close network of the manufacturing firms and the other supporting firms in the cluster can be attributed to the positive absorptive capacity. The results of the mediation analysis clearly indicate that the absorptive capacity actually mediates the Cluster Institutional isomorphic pressure towards the ERP adoption. Our finding is supported by the similar finding of Nevo et al., (2007), that firms see tangible benefits from using external IT consultants only when the level of existing internal IT capabilities support. From the various types of mediation effects discussed by Zhao et al., (2010), the outcome of this study can be understood to be a complementary mediation, because, in addition to the positive and significant indirect influence of isomorphic pressure, the relationship between the Isomorphic pressure, absorptive capacity and ERP adoption are all found to be positive and significant.

\section{Implications}

With many studies recommending the need for ERP for the firms to be competitive and obtain a substantial business performance, the knitwear garments SME cluster has already started adopting ERP. This initiative has led to a stronger regulatory pressure that arises out of Cluster Institutional isomorphism and has become a driving force for stronger ERP adoption. The Cluster Institutional isomorphic pressures tend to have more influence on SME's than what the large businesses have because of their higher interdependency and being a weaker partner (Saunders and
Hart, 1993). Therefore, most SMEs are under pressure to adopt ERP, if its business partners mandate or recommend it to do so. Though larger firms have enough justification on the requirement, the economic strength and a suitable ERP solution, the SME's still find many obstacles in adopting the ERP. The most common obstacle that is felt is that there is no right solution that suit to the characteristics of the SMEs, such as their size and a degree of integration. The notable characteristics of this knitwear cluster is it high disintegration (Joshi and Singh, 2010). The initiatives promoted for finding a proper ERP package that suits to the processes and unique practices seems to be disintegrated. At present, the initiatives in the cluster are still focused on the basic ICT. Following the suggestion of Peppard and Ward (2004), the firms need to move from the basic ICT to a strategic level enterprise systems. Software as a service (SaaS) model of ERP has been identified as an economic solution for small and highly disintegrated business. The business can install enough number of licensed nodes and can utilise only modules required for the processes that they carry out internally. With the availability of the right product, the study prescribes that the institutional members such as government, association, and other agencies, when induce a regulatory pressure, will drive the ERP adoption in the cluster largely. The government has made it mandatory for certain e-governance such as tax payment, Import export licensing etc. Similar regulations on Customs and Excise Duties can encourage the use of ERP.

The adoption of ERP is likely to be rigorous, when promoted by the trade association. SaaS model of software development that is designed specifically for the knitwear garments cluster is the need of the hour and this kind of collective requirement can only be coordinated by the trade associations. Therefore, trade associations need to be more proactive and aggressive in supporting the development of an ERP solution and promote it. The cluster development agencies, world bank, etc have already taken a role in the 
promotion of ICT among the knitwear units. Yet the firms may require moving to the next level of adopting integrated solution such as ERP. We quote Hurtado et al., (2010) that the higher the isomorphic pressures the higher the level and speed of web technology adoption and normative pressures exert the strongest influence on these processes.

The absorptive capacity has been found to be a complementing factor to ERP adoption. Therefore, along with the Cluster Institutional isomorphic pressures the absorptive capacity needs to be developed. This will require the joint development of vocational - technical college curricula that trains people with ERP skills. The vendors and consultants should join in providing training support not only within the implementing firm but also in generating skilled human resource. The few adopted firms are finding it difficult to retain the employees who are trained in ERP. They feel the pressure in retaining them and sometime end up in winding up the ERP support for lack of operators. This situation can be avoided, if human resource is available with proper training on the ERP software. This may require the industry to adopt a common solution.

\section{Contributions of the study}

This study has contributed to the empirical validation of the mediating role of absorptive capacity for cluster's Institutional isomorphic pressure towards ERP adoption and their direct influence. The outcome of the study is a validated model of the motivating factors for ERP adoption of a SME knitwear garments cluster. The results direct at a possible solution to address the gap in creating a motivation for ERP adoption. To practice, this study reiterates a need for agencies and the universities in and around the cluster to take up ERP curriculum to develop ERP professionals and train the employees in ERP.

\section{Limitations and future direction}

Many factors contribute to build a motivation to adopt ERP. This study takes a narrow view and looks at two factors, Cluster Institutional isomorphic pressure and absorptive capacity. A mediation model was proposed for the study and the statistical analysis is done by structural equation modelling technique. The indirect, direct and the total effect in AMOS software package is used. The significance level of the results is checked by bootstrapping technique. This study can be extended by including other motivating variables and still test the mediating effect of them. The mediation analysis can be cross-validated using other statistical techniques.

\section{Conclusion}

Prior studies have found that the penetration of ERP in the knitwear garments cluster is less than 30\% among the SME's (Roy and Biswas, 2007). Nevertheless, the need for ERP adoption has been felt due to the economic situation, which demands for more productivity, cost efficiency and keeping up schedule etc. There is also a pressure from the neighbouring countries gaining cost leadership and the business. The knitwear garments cluster is a matured cluster with an interwoven network of business partners in the supply chain and stronger trade associations. This study proposed to identify the characteristics of the SME cluster of the knitwear garment industry that motivate the ERP adoption. The review of literatures identifies that the industrial clusters experience an institutional isomorphic pressure that forces them to be homogeneous. The entrepreneurial transformation of the cluster that was taken for the study also throws another question on the absorptive capacity of the firms in adopting sophisticated technologies. A conceptual model depicting the relationship between the isomorphic pressure and the ERP adoption along with absorptive capacity as mediating the relationship is proposed for the study. A survey was conducted among the knitwear garment firms to measure the status of the ERP adoption, absorptive capacity and the Cluster institutional isomorphic pressures. The data were analysed by using structural equation modelling technique. To test the mediation effect, direct, indirect and total 
effects of the variables are calculated in the AMOS software. The results show that there is a direct influence of isomorphic pressure on ERP adoption and as well, the absorptive capacity mediates in such a way that it complements the institutional forces in ERP adoption. The results also indicate that the mechanism of the institutional forces is rather identified as the agents of pressure. The government and the supplier pressure are not seriously felt by the industry. Whereas the pressure from the buyers/customers is fully recognised; and the industry obliges to such requirements. The role of the trade associations, media influence and the management consultants are appreciated in motivating the firms to adopt ERP. Interviews with various players in ERP promotion in the industry reveal that there is a large gap in the availability of right software that will suit their nature of operations and their size. The availability of the trained personnel is also a matter of concern for the ERP adoption. This paper also identifies a few limitations of the study and recommends the future direction for further research.

\section{References}

1. Arbuckle, J. L. (2009), Amos 18 User's Guide, Chicago, IL: SPSS Inc.

2. Arthur, B. (1990), 'Silicon Valley locational clusters: When do increasing returns imply monopoly?' Mathematical Social Sciences, 19, 235-251.

3. Baptista, J., Newell, S. and Currie, W. (2010), 'Paradoxical effects of institutionalisation on the strategic awareness of technology in organisations,' The Journal of Strategic Information Systems, 19 (3), 171-183.

4. Baron, R.M. and Kenny, D.A. (1986), 'The Moderator-Mediator variable distinction in Social Psychological research: Conceptual, strategic, and statistical considerations,' Journal of Personality and Social Psychology, 51, 1173-1182.
5. Benders, J., Batenburg, R. and Van der Blonk, H. (2006), 'Sticking to standards; Technical and other Isomorphic Pressures in Deploying ERP-systems,' Information and Management, 43, 194- 203.

6. Bentler, P.M. (1990), 'Comparative fit indexes in structural models,' Psychological Bulletin, 107 (2), 238-246.

7. Bentler, P.M. and Bonett, D.G. (1980), 'Significant tests and goodness of fit in the analysis of covariance structures,' Psychological Bulletin, 88 (3), 588-606.

8. Bharati, P. and Chaudhury, A. (2011), 'Impact of institutional pressures on absorptive capacity of a firm and Web 2.0 assimilation,' Proceedings of the Seventeenth Americas Conference on Information Systems, Detroit, August 4-7, 201, Paper 106. http://aisel.aisnet.org/amcis2011_submiss ions/106

9. Browne, M. W. and Cudeck, R. (1993), Alternative ways of assessing model fit, Testing structural equation models, Bollen, K.A. and Long, J.S. (Eds.), Sage, Newsbury Park, CA, pp. 136-162.

10. Buonanno, G., Faverio, P., Pigni, F., Ravarini, A., Sciuto, D. and Tagliavini, M. (2005), 'Factors affecting ERP system adoption: A comparative analysis between SMEs and large companies,' Journal of Enterprise Information Management, 18(4), 384-426.

11. Cairncross, F. (1997), The Death of Distance. London: Orion Business Books.

12. Caldas, M. and Wood, T.J. 2000), 'Fads and fashions in management: the case of ERP,' SAR - Journal of Business Administration, 40 (3) 8-17

13. Caldas, M. and Wood, T.J. (1999), 'How consultants can help organizations survive the ERP frenzy,' Communication in Academy of Management, Chicago.

14. Chari, S. (2000), "The agrarian origins of the Knitwear industrial cluster in 
Tiruppur, India,' World Development, 28 (3), 579-599.

15. Cluster Ecosystem. (n.d.). [Online], [Retrieved December 22, 2014], http://www.tirupurbds.com/ces.aspx

16. Cohen, W. M. and Levinthal, D.A. (1990), 'Absorptive capacity: A new perspective on learning and innovation,' Administrative Science Quarterly, 35 (1), 128-152.

17. Craig Standing, Ian Sims and Peter Love. (2009), 'IT non-conformity in institutional environments: E-marketplace adoption in the government sector,' Information \& Management, 46, 138-149.

18. Dillman, D. A. (2007), Mail and internet surveys: The tailored design method. Wiley, Hoboken, N.J.

19. DiMaggio, P.J. and Powell, W.W. (1983), 'The iron cage revisited: Institutional isomorphism and collective rationality in organizational fields,' American Sociological Review, 48 (2), 147160.

20. Elangovan, N. (2012), 'Cluster Institutional Isomorphic Pressures: A case of Tirupur knitwear cluster,' Research Journal of Social Science and Management, 2 (4), 95-102.

21. Elbertsen, L., Benders, J.and Nijssen, E. (2006), 'ERP use: exclusive or complemented?' Industrial Management and Data Systems, 106 (6), 811-824.

22. Fashion Knits: Enhancing Efficiency. (n.d.), [Online], [Retrieved December 22, 2012], http://nmccvikas.gov.in/Ludhianahosiery/FashionKnits.html.

23. Gabbay, S. M., Talmud I. and Raz, 0 . (2001), 'Corporate social capital and corporate strategy: The case of Israeli hightechnology start-ups,' Research in the Sociology of Organizations, 18, 135-150.

24. Guiliani, E. (2005), 'Cluster Absorptive Capacity: Why do some clusters forge ahead and others lag behind?' European Urban and Regional Studies, 12, 269-288.

25. Hayes, A. F. (2009), 'Beyond Baron and Kenny: Statistical mediation analysis in the new millennium,' Communication Monographs, 76, 408-420.

26. Hung, S-Y., Chang, S-I. and Lee, P-J. (2004), 'Critical factors of ERP adoption for Small- and Medium- Sized Enterprises: An Empirical Study,' Proceedings of Pacific Asia Conference on Information Systems, July 8-11, Shanghai, China.

27. Hurtado, J.M., Camara, S.B. and Gonzalez, J.L.G. (2010), 'Institutional rationales on speed and level of web technology adoption,' International Journal of Information Technology and Management, 9 (2), 185-202.

28. Joshi, R. N. and Singh, S.P. (2010), 'Estimation of total factor productivity in the Indian garment industry,' Journal of Fashion Marketing and Management, 14 (1), 145-160.

29. Kamhawi, E. M. (2008), 'Enterprise resource planning systems adoption in Bahrain: Motives, benefits, and barriers,' Journal of Enterprise Information Management, 21 (3), 310-334.

30. Katharina, K., Sabine, M. and Fiona, R. (2009), 'The effects of regulatory pressure on Information System adoption success: An institutional theory perspective,' Proceedings of the $17^{\text {th }}$ European Conference on Information Systems, 1-12.

31. Kouki, R., Poulin, D. and Pellerin, R. (2007), 'ERP assimialtion levers: the case of a manufacturing food company,' Proceedings of the 19th International Conference on Production Research, July 29, Valparaiso, Chile.

32. Li Chao and Wang Xiaofei (2009), 'High-tech enterprise cluster's innovation and isomorphism: A case study of zhongguancun software park identity struggle,' Proceedings of the 16th International Conference on Industrial Engineering and Engineering Management 
(IEandEM 09), October 21, Beijing, China, 646-650.

33. Liang, H., Saraf, N., Hu, Q. and Xu, W. (2007), 'Assimilation of Enterprise systems: the effect of institutional pressures and the mediating role of top management,' MIS Quarterly, 31 (1), 59-87. 34. Marshall, A. (1920), Principles of economics. MacMillan, London.

35. Meyer, J.W. and Rowan, B. (1977), 'Institutionalized organizations: Formal structure as myth and ceremony,' American Journal of Sociology, 83 (2), 340-63.

36. Nevo, S., Wade, M.R. and Cook, W.D. (2007), 'An examination of the trade-off between internal and external IT capabilities,' The Journal of Strategic Information Systems, 16 (1), 5-23.

37. Pan, J.M. and Jang, Y.W. (2008), 'Determinants of the adoption of Enterprise Resource Planning within the Technology-Organization-Environment framework: Taiwan's Communication Industry,' Journal of Computer Information System, 94-102.

38. Peppard,J., Ward, J. (2004), 'Beyond strategic information systems: towards an IS capability,' The Journal of Strategic Information Systems, 13 (2), 167-194.

39. Phang, C.W., Kankanhalli, A. and Ang, C. (2008), 'Investigating organizational learning in eGovernment projects: A multitheoretic approach,' The Journal of Strategic Information Systems, 17 (2), 99123.

40. Poba-Nzaou, P., Raymond, L. and Fabi, B. (2008), 'Adoption and risk of ERP systems in manufacturing SMEs: a positivist case study,' Business Process Management Journal, 14 (4), 530-550.

41. Porter, M. E. (1990), The competitive advantage of nations,' Free Press, New York.

42. Porter, M. E. (1998), 'Cluster and the new economic of competition,' Harvard
Business Review, November-December, 7890.

43. Pouder, R. and John, C. H. (1996), 'Hot spots and blind spots: Geographical clusters of firms and innovation,' The Academy of Management Review, 21 (4), 1192-1225.

44. Premkumar, G. (2003), 'A metaanalysis of research on Information Technology implementation in small business,' Journal of Organizational Computing and Electronic Commerce, 13 (2), 91-121.

45. Project Vikas (n.d.). [Online], [Retrieved December 22, 2010], http://clusters.org/pv/tirupur.asp?cluster =tirupur.

46. Rajendran, R. and Elangovan, N. (2012), 'Response of small enterprises to the pressures of ERP adoption,' International Journal of Enterprise Information Systems, 8 (1), 28-50.

47. Ravichandran, T., Han, S. and Hasan, I. (2009), 'Effects of institutional pressures on information technology investments: An empirical investigation,' IEEE Transactions of Engineering and Management, 56 (4), 677-691.

48. Raymond, L. and Uwizeyemungu, S. (2007), 'A profile of ERP adoption in manufacturing SMEs. Journal of Enterprise Information Management, 20 (4), 487-502.

49. Rogers, E.M. (1995), Diffusion of innovations (Fourth Edition). Free Press, New York.

50. Ross, J.W. and Vitale, M.R. (2000), 'The ERP revolution: surviving vs. thriving,' Information Systems Frontiers, 2 (2), 233241.

51. Roy, S. and Biswas, S., (2007), 'Collaborative ICT for Indian business clusters,' Poster papers of 16th International World Wide Web Conference (WWW2007), May 8-12, Banff, Canada pp. $1115-1116$. 
52. Rusten, G. and Bryson, J.R. (2007), Understanding the relationship between information and communication technology and the behaviour of firms located in regional clusters, The Handbook of Service Industries, Bryson, J.R. and Daniels, P.W. (Eds.), Edward Elgar Publishing Limited, Cheltenham, UK, pp.311-330

53. Saunders, C. and Hart, P. (1993), 'Electronic Data Interchange across organizational boundaries: Building a theory of motivation and implementation,' Proceedings of Twenty First Annual Conference, Administrative Sciences Association of Canada (ASAC), Lake Louise, Canada.

54. Sedera, D. and Gable, G.G. (2010), 'Knowledge management competence for enterprise system success,' The Journal of Strategic Information Systems, 19(4), 296306.

55. Sobel, M. E. (1982), 'Asymptotic confidence intervals for indirect effects in structural equation models,' Sociological Methodology, 13, 290-312.

56. Srivardhana, T. and Pawlowski, S.D. (2007), 'ERP systems as an enabler of sustained business process innovation: A knowledge-based view, The Journal of Strategic Information Systems, 16 (1), 5169.

57. Strand, D. and Meyer, J. W. (1994), Institutional conditions for diffusion, Institutional environments and organizations: Structural complexity and individualism, Scott, W. R. and Meyer, J.W. (Eds.), Sage Publications Inc, California.

58. Suh, H. and Kym, H. (2001), 'The impact of absorptive capacity of the firm upon ERP adoption,' : Proceedings of the Pacific Asia Conference on Information Systems (PACIS-2001), June 20-22, Seoul, Korea. pp. 87-107.
59. Technology Upgradation Fund Scheme (TUFS) for Textile and Jute Industries (n.d.). [Online], [Retrieved December 22, 2010], http://www.txcindia.com/html/booklet_of _tufs.htm.

60. Teo, H. H., Wei K.K. and Benbasat, I. (2003), 'Predicting intention to adopt interorganizational linkages: an institutional perspective,' MIS Quarterly, 27 (1), 19-49.

61. Tirupur Knitwear Cluster. (n.d.). [Online], [Retrieved December 20, 2010], http://www.nmcc-

vikas.gov.in/Cluster/TirupurKnitwear.aspx

62. Tucker, L. R., Lewis, C. (1973), 'The reliability coefficient for maximum likelihood factor analysis,' Psychometrika, $38,1-10$.

63. Van Den Bosch, F.A.J., Van Wijk, R. and Volberda, H.W. (2003), Absorptive capacity: Antecedents, models, and outcomes, Handbook of Organizational Learning and Knowledge Management, Easterby-Smith, M. And Lyles, M.A. (Eds.), Blackwell, Oxford, pp. 278-301.

64. Weaving Success with IT Adoption. (n.d.), [Online], [Retrieved December 20, 2010], http://nmccvikas.gov.in/Ludhianahosiery/Cluster.html

65. Wood, T. and Caldas, M. (2001), 'Reductionism and complex thinking during ERP implementations,' Business Process Management Journal, 7 (5), 387-93.

66. Zahra, S.A. and George, G. (2002), 'Absorptive capacity: A review, reconceptualization, and extention,' Academy of Management Review, 27 (2), 185-203.

67. Zhao, X. Lynch Jr, J.G. and Chen, Q. (2010), 'Reconsidering Baron and Kenny: Myths and truths about mediation analysis,' Journal of Consumer Research, 37, 197-206. 